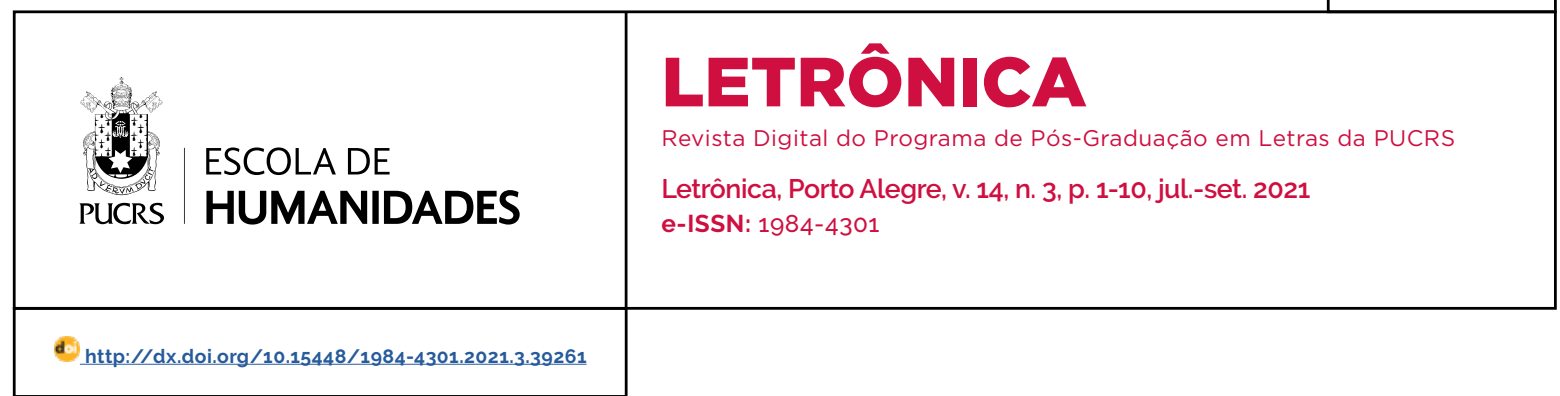

SEÇÃO: ARTIGO

\title{
Decolonizando a violência contra as mulheres subalternas em Elvira Vigna
}

\author{
Decolonizing violence against subaltern women in Elvira Vigna
}

\section{Gardênia Dias Santos ${ }^{1}$ orcid.org/0000-0002-2667-1246 gardenia.diass@gmail.com}

\section{Carlos Magno Gomes ${ }^{1}$}

orcid.org/0000-0001-9070-9010 calmag@bol.com.br

Recebido em: 29 set. 2020 Aprovado em: 28 abr. 2021 Publicado em: 9 nov. 2021.

\section{(c) (1)}

Artigo está licenciado sob forma de uma licença Creative Commons Atribuição 4.0 Internacional.
Resumo: Este artigo tem por objetivo identificar como a violência contra as personagens femininas subalternas que está retratada na obra Como se estivéssemos em palimpsesto de putas (2016), de Elvira Vigna. Partimos de uma abordagem feminista decolonial com o intuito de identificar as estratégias narrativas usadas pela narradora para explicitar as opressões aniquiladoras do protagonista, João, que impõe sua masculinidade por meio de sexo pago. Como subsídios teóricos, traremos os estudos de Lugones (2019) sobre a decolonização do gênero; de Segato (2003), acerca da violência estrutural que silencia as mulheres; e de Hutcheon (1993), sobre a paródia como uma estratégia politica de revisão feminista. Palavras-chave: Feminismo decolonial. Violência contra a mulher. Masculinidade. Elvira Vigna.

Abstract: This article aims to identify how gender violence against women is represented in the novel Como se estivéssemos em palimpsesto de putas (2016), written by Elvira Vigna. We start from a decolonial feminist approach in order to identify the narrative strategies used by the narrator to make explicit the annihilating oppressions of the protagonist, João, who imposes his masculinity through paid sex. As theoretical subsidies, we will bring the studies of Lugones (2019) on the decolonization of gender, Segato (2003) on structural violence that silences women, and Hutcheon (1993) on parody as a political strategy of feminist revision. Keywords: Decolonial feminism. Violence against women. Masculinity. Elvira Vigna.

\section{Introdução}

As produções literárias de autoria feminina contemporânea, ao inserirem em suas ficções registros de violência contra a mulher, têm questionado os valores sociais que dão sustentação a esse tipo de prática punitiva imposta estruturalmente aos diferentes tipos de corpos femininos. Observamos que, nos últimos anos, muitas autoras apresentam obras que revisam as normatizações que controlam as identidades femininas, desnudando "fantasias" masculinas naturalizadas por práticas de abusos de gênero.

Entre essas autoras, destacamos Conceição Evaristo, com o livro de contos Olhos d'água (2014), que reúne narrativas que denunciam os diferentes tipos de violência físico-sexual contra a mulher negra; Elvira Vigna, com o romance Como se estivéssemos em Palimpsestos de putas (2016), que retoma o debate acerca de valores morais que silenciam a voz da garota de programa; e Patricia Melo, com o romance Mulheres 
empilhadas (2019), que parte de feminicidios reais para construir uma trama ficcional que denuncia o machismo estrutural. Essas narrativas trazem posturas questionadoras dos diferentes mecanismos de violência contra a mulher. No desenrolar das trajetórias das personagens femininas, essas obras, ao confrontarem com os aparatos ideológicos hegemônicos, apontam o quanto os padrões alinhados e reproduzidos em função do patriarcado impulsionam as diferentes sistemáticas de aniquilamento feminino.

O processo de aniquilamento passa pela normatização de a identidade feminina ser submissa à masculina. Tal regulação de gênero também está vinculada a dispositivos interseccionados que ampliam ainda mais sua vulnerabilidade quando incluimos reflexões sobre as categorias de classe, raça, sexo e gênero. Segundo María Lugones (2019), a violência contra mulheres vulneráveis é normatizada por valores que vão além da masculinidade opressora e está atrelada a questões de classe e etnia. Tais tensões também são representadas nas obras de Vigna, Evaristo e Melo, que denunciam valores e principios patriarcais ao ironizarem as representações masculinas machistas e excludentes.

Esses questionamentos fazem parte da agenda de debates e lutas feministas e têm ganhado mais espaço na imprensa e nas redes sociais através de diversas campanhas contra estupros e feminicídios. No campo dos estudos antropológicos, os conceitos de "violência de gênero", de Rita Segato (2003), e de "excesso de masculinidade", desenvolvidos por Lia Zanotta Machado (1998), nos permitem analisar como essa violência é infligida às mulheres por meio de contratos sociais que simbolicamente ainda consideram o corpo da mulher uma extensão da masculinidade. Para ampliar esse debate, partimos das abordagens sobre a "decolonização de gênero", proposta por María Lugones (2019), com o foco no combate às naturalizações das identidades femininas submissas e subalternas e na revisão das relações hierarquizadas pela colonialidade patriarcal.

A critica literária feminista tem nos fornecido ferramentas indispensáveis à realização de uma interpretação do texto literário comprometida em desconstruir o caráter discriminatório de gênero. A postura contestatória dessa forma de crítica tem se constituido como uma estratégia de resistência acadêmica, pois "se as relações entre os sexos se desenvolvem segundo uma orientação política de poder, também a crítica literária feminista é profundamente política na medida em que trabalha no sentido de interferir na ordem social" (ZOLIN, 2009, p. 182). Tal postura politizada da crítica feminista nos oferece subsídios para a construção de nossos argumentos a favor da decolonização de gênero no texto literário.

O diálogo entre essa teoria feminista e a perspectiva revisionista dos papéis de gêneros promovidos pelas produções de autoria feminina contemporânea nos permite contestar a violência de gênero sofrida pelas personagens femininas. Sendo assim, a decolonização das representações masculinas opressoras retratadas nessas obras visa contestar as normas de controle e punição das mulheres oriundas de uma visão patriarcal que insiste em perpetuar a submissão feminina e de seus corpos ao desejo masculino.

Partindo dessas reflexões, pretendemos analisar como a violência contra a mulher é questionada no romance Como se estivéssemos em palimpsesto de putas (2016), de Elvira Vigna, a partir do estudo das estratégias narrativas que deslocam os valores tradicionais para decolonizar as identidades de sexo/gênero. Quanto à violência de gênero praticada contra as personagens femininas subalternas, reconhecemos representações que desvelam as desigualdades de gênero ao registrar performances opostas às amarras de uma sociedade misógina. Elódia Xavier, ao analisar o quanto esses atos violentos repercutem nos corpos, argumenta que as escritoras fazem do "corpo subalterno um instrumento de denúncia, ao transformarem a vida miserável numa narrativa que transgride o modelo canônico e se coloca como um gênero de fronteira, expressão de uma mulher oprimida" (XAVIER, 2007, p. 48-49).

A obra de Elvira Vigna traz importantes reflexões sobre temas atuais referentes às questões identitárias e seus deslocamentos sociais. A critica 
literária tem destacado essas peculiaridades da obra de Vigna como uma desconstrução da masculinidade. Por exemplo, João, protagonista da obra em análise, tem um perfil de homem "sempre frustrado, pois nunca realiza a concepção que tem de masculinidade, buscando nas garotas de programa uma forma de poder ser mais através delas, usando-as para sobrepor (des)ilusões de si mesmo" (SILVEIRA, 2017, p. 178). A opressão imposta por um personagem masculino em crise reforça a proposta estética na paródia dessa obra.

O jogo de sentidos do título "como se estivéssemos" já nos dá uma pista que o olhar decolonizado é o masculino. A narradora filtra as concepções de corpo feminino que João e seus amigos constroem acerca das mulheres com quem se relacionam e deduz que, para eles, as mulheres não passam de putas. Em nossa análise, observaremos como a violência é legitimada e naturalizada pelos discursos dos personagens masculinos e o quanto suas identidades opressoras estão fortemente atreladas a valores como virilidade e honra.

\section{Revisando as contradições entre a violência e a construção masculina}

Lia Zanotta Machado, em "Masculinidade, sexualidade e estupro" (1998), afirma que para a masculinidade violenta a "virilidade em excesso" e o "imaginário" da violência em nome da "honra" delineiam as regras de reciprocidade estabelecidas como código de dádiva e divida, de honra e vingança, de aliança e hierarquia, ou seja, regulações que são desrespeitadas acarretam o uso da violência como meio de repor a disciplina ao corpo e à sexualidade da mulher.

Rita Laura Segato ressalta que, em uma sociedade "sexualmente" ordenada, os constantes chamamentos à disciplina imposta pelo sistema de economia simbólica tem na violência moral a forma mais eficiente dos mecanismos de controle social e de reprodução das desigualdades porque "[...] en el universo de las relaciones de género, la violencia psicológica es la forma de violencia más maquinal, rutinar ia e ir reflexiva y, sin embargo, constituye el método más eficiente de subordinacion e intimidación" (SEGATO, 2003, p. 7).

Todavia, é o conjunto de todas as formas de violência contra a mulher que garantem a força da dominação masculina. Desta maneira, o homem recorre a diversas formas de violência, sejam as observáveis, como agressões fisicas e morais, que antecipam o feminicidio conjugal; sejam as implícitas, como o aniquilamento simbólico de uma mulher que foi vítima de abuso sexual. Nesse sentido, a perspectiva do feminismo decolonial tem contribuido para o questionamento desses prismas ao promover os diferentes tipos de violência naturalizadas pelas regras sociais.

Além dessa abordagem, buscamos respaldo na concepção interseccional das questões femininas por entender que as análises isoladas desenvolvidas a partir de categorias como raça, classe e gênero tendem a ocultar a amplitude das violações. Ao reivindicar a intersecção dessas categorias, o feminismo decolonial vai além da lógica dicotômica e hierárquica do pensamento hegemônico e abre brechas para o questionamento de normas que privilegiam a masculinidade opressora conforme Heloísa Buarque de Hollanda (2018).

A interseccionalidade das violências, segundo Carla Akotirene, permite às feministas criticidade política a fim de "[...] compreenderem a fluidez das identidades subalternas impostas a preconceitos, subordinações de gênero, de classe e raça e às opressões estruturantes da matriz colonial moderna da qual saem" (2019, p. 24). Portanto, ao se levar em consideração as interseções identitárias, conseguimos apontar detalhes referentes às opressões sofridas pelos diferentes grupos de mulheres. Nesse debate acerca das diferentes identidades femininas representadas na obra de Vigna, retomamos algumas reflexões de Spivak sobre como podem ser articuladas as vozes das mulheres silenciadas, visto que é estratégico identificarmos mecanismos que evitem filtros ideológicos próprios do "falar por" (SPIVAK, 2010, p. 31).

Pela perspectiva decolonial, a tentativa de resgatar a fala das prostitutas silenciadas pelo discurso machista é uma estratégia de resistência aos discursos patriarcais e conservadores. Sendo 
assim, "descolonizar o gênero é necessariamente uma práxis. É decretar uma crítica da opressão de gênero racializada, colonial e capitalista heterossexualizada visando uma transformação vivida do social" (LUGONES, 2019, p. 363). Ao desvelar a violência de gênero, o feminismo não apenas fornece narrativas sobre a opressão de mulheres, mas também materiais que permitem uma visão crítica das estratégias de domínio masculino.

Por esse paradigma, a Crítica Literária Feminista amplia os horizontes culturais de uma obra ao optar por desnudar e desconstruir os discursos que circunscrevem a opressão feminina. No âmbito literário, Elódia Xavier destaca a importância de trazer representações femininas subalternas à cena, pois "[...] a singularidade e solidão dessa mulher subalterna", reforça sua posição social deslocada e/ou marginalizada pelas normas gênero (XAVIER, 2007, p. 49). Lúcia Zolin, por sua vez, acredita que as escritoras exploram estratégias que dialogam com esse olhar desconstrutor quando optam por mecanismos estético-temáticos, que visam desestabilizar a ordem androcêntrica, e fazem-no explorando representações femininas que não "[...] se reduzem a reduplicações ideológicas de papéis de gênero, sancionadas pelo senso comum, mas que espelham a multiplicidade e a heterogeneidade que marcam o modo de estar da mulher na sociedade contemporânea" (ZOLIN, 2009, p. 182).

Nas trilhas da decolonização, seguimos os passos de uma abordagem contra-hegemônica que permite levar em consideração a intersecção das múltiplas violências dirigidas a um único individuo. Desarticular esse tipo de violência é fundamental para uma visão mais ampla da violência estruturada, pois "é inconcebivel, para mim, que certa parte de minha identidade possa se beneficiar com a opressão de outra" (LORDE, 2019, p. 235).

Nos textos literários, uma estratégia de decolonização da violência de gênero mais utilizada pelas escritoras brasileiras é uma abordagem paródica dos valores masculinos. Para Linda Hutcheon, a arte paródica está associada ao feminismo de desconstrução, pois essas produções
Usam e abusam, estabelecem e depois desestabilizam a convenção de maneira paródica, apontando autoconscientemente para os próprios paradoxos e o caráter provisório que elas são inerentes, e, é claro, para sua reinterpretação crítica ou irônica em relação à arte do passado (HUTCHEON, 1991, p. 43).

Em outras palavras, as autoras, ao darem ênfase às representações que ironizam as verdades masculinas, estão revisando valores do passado por uma ótica feminista. No caso das personagens femininas subalternas, as autoras evidenciam o quanto essas mulheres vivem em maior estado de vulnerabilidade social. Sendo assim, no que se refere às garotas de programa, acreditamos que Elvira Vigna tenta lhes darvoz ao fazer um paralelo entre os diferentes tipos de violência que as mulheres sofrem por homens opressores, machistas e egoistas.

A seguir, analisaremos como essas questões são destrinchadas na obra selecionada.

\section{As opressões das personagens subalternas}

Contra normas e condutas machistas, a proposta contra-hegemônica de resistência do feminismo decolonial se mostra bastante promissora, pois enfoca na "subjetividade/intersubjetividade para revelar que, desagregando opressões, desagregam-se as fontes subjetivas-intersubjetivas de agenciamento das mulheres colonizadas" (LUGONES, 2019, p. 363). Assim, a decolonização de gênero enfatizada por esse viés feminista nos permite desarticular opressões tanto individuais quanto coletivas direcionadas às mulheres.

Tal estratégia é usada por Elvira Vigna em seu romance Como se estivéssemos em palimpsesto de putas, que traz à cena os relatos do técnico em TI (especialista em Tecnologia da Informação), João, acerca de suas aventuras com garotas de programa e que nos são transmitidas de forma crítica por uma narradora, que não tem seu nome revelado. Em meio às confissões do protagonista, somos conduzidos pela narradora a evidenciar como se estabelecem as relações desiguais entre João e as mulheres, pois não se reconhece a subjetividade feminina e sempre violenta a existência das mulheres com quem se envolve. 
Lola, sua esposa, sofre constantemente violência simbólica de João que não abre espaço para as subjetividades da companheira, uma vez que está imbuido de sua sina de predador sexual. Para a narradora, as agressões sutis de João contra Lola são formas de silenciamento e estão estrategicamente relacionadas as suas buscas incessantes por sexo. No caso das garotas de programa, João age de forma mecânica como se fosse programado para repetir atos que lhe resgatam a virilidade. Ele experimenta muita ansiedade nas suas constantes buscas, pois nunca está satisfeito.

Diante de um homem mecânico, as prostitutas são duplamente vítimas tanto da violência social, que as marginaliza por se prostituírem, e a misógina, que as rebaixa por usarem seus corpos como bem entendem. Além de serem vítimas de João e de seus colegas de empresa, essas mulheres são estigmatizadas como mulheres de segunda classe, pois têm seu corpo aniquilado simbolicamente pelo que fazem. Tal visão machista da prostituta como uma mulher subalterna reforça os vários preconceitos que esses sujeitos sofrem, já que as mulheres subalternas estão "ainda mais profundamente na obscuridade" (SPIVAK, 2010, p. 15).

Ao pôr em xeque a construção masculina opressora e pautada por valores androcêntricos, Elvira Vigna evidencia o quanto João e seus colegas abusam de sua situação econômica privilegiada, pois buscam com a mercantilização dos corpos das garotas de programas desumanizá-las: "Sai a garota, os saltos, a saia curta, o decote, a risada presa na boca. E atrás, em triunfo, Cuica. [...] 'Essa è a'. [...] Shirley, Vanessa, Lara, Giselle, Priscila, Liane. Nicka" (VIGNA, 2016, p. 84). A descrição das partes da garota de programa reforça essa desumanização imposta pela exploração sexual de mulheres subalternas. Tal estratégia narrativa visa ironizar a visão masculina e denunciar a insignificância das prostitutas para homens que só pensam no seu prazer.

Ao desvelar tal violência como parte do padrão cultural que reproduz a punição contra a mulher, expõe-se o quanto ela está relacionada à hon- ra masculina. Nesse caso, Vigna brinca com os padrões de masculinidade a partir da imposição da opressão para dominação das mulheres. Essa estratégia de denúncia demonstra o quanto a escritora, ao trazer para o texto a representação de uma masculinidade em crise, nos permite refletire revisar os valores sociais que sustentam esse tipo de problema social. Nesse sentido, ao desvelar essa identidade masculina em crise, a autora traz uma releitura da cegueira masculina de disputa entre seus pares, do culto da virilidade e da imposição da heterossexualidade como a dominante.

No processo de exploração das prostitutas, o controle econômico é tido como fundamental para homens manterem o controle da situação: "[...] faz questão de dar o dinheiro./ 'Ah, não precisa'./ Precisa. Dar o dinheiro é uma última tentativa de recuperar um clima. Ele, o fodão, ela, a buceta paga. Não funciona./ É tudo mais ou menos" (VIGNA, 2016, p. 175). O abuso econômico está relacionado ao modelo de colonização de gênero, pois reforça a premissa de que o feminino é uma extensão da masculinidade. Essa perspectiva é satirizada pela narradora quando descreve que João e seus colegas de firma estão em uma churrascaria acompanhados por uma garota de programa: Faz sentido uma churrascaria. Não só por ser
churrascaria. Carnes à mostra e tal. Mas por
ser um clichê de carnes à mostra. [...]
Quando vejo a cena dos três mais a garota, é
nesse restaurante que vejo. Todos tão chiques.
Porque a garota senta e eles fazem o ritual do
vinho e da carne sangrenta e uma vez tudo es-
tabelecido, quem é homem (os que falam com o
garçom), quem é rico (os que falam com o garçom)
e quem está lá para servir (a garota e o garçom),
todos ficam na mesa, esperando os pratos.

E dizem, entre eles, como se a garota não estivesse presente, que o peito dela parece de silicone (VIGNA, 2016, p. 85-86).

Ao utilizarem as mulheres em seus jogos de poder, os personagens masculinos buscam a autoafirmação de suas masculinidades. Nessa disputa, todos só conseguem falar aqui a mesma língua: a de aniquilamento da mulher. Conforme Rita Segato, é na capacidade de dominar e exibir seu prestigio perante seus iguais que se encontra 
a subjetividade dos homens bem como na sua posição hierárquica, que constitui o que denominamos de masculinidade (2003).

Em grande parte dessa narrativa, deparamo-nos com um protagonista inseguro, apesar de se construir como "superior". Segundo a narradora, as histórias contadas por ele têm como único propósito demonstrar "[...] a maravilha que ele é. João é uma maravilha segundo ele mesmo, porque busca, para a vida dele, experiências interessantes e transgressoras" (VIGNA, 2016, p. 31). Além disso, ele também se considera um "herói" ao "salvá-las": "A garota pediu por favor para eu sair com ela, porque se eu não saísse, ela ia ter de acabar aceitando o programa com algum velho gordo qualquer, então ela. Por favor. Por favor. E eu saí. E ela teve de pagar o favor" (VIGNA, 2016, p. 159).

A interposição de vozes, da narradora e de João, reforça o jogo dos pontos de vista que dão sustentação ao romance. No principio, a narradora se coloca como uma ouvinte das aventuras do amigo e de suas formas de opressão. Todavia, à medida que a narrativa se desdobra, a ironia ganha espaço e a masculinidade opressora abre caminhos para um homem em crise com sua sexualidade. Na narrativa de Vigna, identificamos o jogo de vozes próprio do romance pós-moderno pois "ao mesmo tempo em que fala de si, esse tipo de narrativa busca soluções sociais" (GOMES, 2010, p. 52). Essa opção estética tem deslocado as verdades e reforça a perspectiva de revisão proposta por esse romance. Nesse jogo, evidenciamos que a objetificação dos corpos femininos é estratégia de manutenção de uma masculinidade produzida coletivamente, pois a afirmação desse sujeito depende da necessidade de rebaixar a existência das mulheres.

Entre as diferentes representações da prostituta, Vigna deixa registrada o quanto essa categoria sofre vários tipos de agressões morais e físicas que fazem parte da violência estrutural. Elas são punidas pela falta de assistência e pelo sequestro de direitos básicos como o acesso à justiça, saúde, inclusão social, aposentadoria e entre outros. No contexto social, os principais motivos para as agressões sofridas pelas profissionais do sexo estão ligados à discriminação da profissão e à falta de dinheiro ou condição social. Em uma pesquisa realizada com profissionais nordestinas sobre as diferentes formas de abusos físicos e morais, constatou-se que $59.5 \%$ das entrevistadas referiram-se à violência verbal; 38,1\% à violência física praticada por qualquer agressor; 25,2\% por parceiro intimo; $16,6 \%$ por familiar/ conhecido; $11,7 \%$ por cliente; $7.9 \%$ por policial. Quanto à violência sexual, 37,7\% das entrevistadas relataram ter sofrido alguma vez na vida (LIMA; MERCHÁN-HAMANN; URDANETA; DAMACENA; SZWARCWALD, 2017, p. 4).

Os estudiosos ainda salientam que o perfil majoritário dessas profissionais é composto por mutheres que se autorreferenciaram como sendo parda e negra, jovem, solteira, com baixo nivel de escolaridade e poder aquisitivo. No livro de Vigna, a questão da raça e do preconceito com a idade das prostitutas também é evidenciada quando se referem às profissionais do sexo da praça Tiradentes: "as prostitutas são mais velhas, mais negras e mais meigas do que qualquer uma que João já tenha conhecido na vida" (VIGNA, 2016, p. 125). Em outra passagem, quando se refere ao seu contato com as prostitutas do México, temos mais um exemplo do quanto mais escura e velhas, menos valem os trabalhos dessas profissionais: "[...] as chicas não são tão chicas./ Mulheres de seus trinta anos" (VIGNA, 2016, p. 139). Aqui estão em jogo os sentidos da palavra garota, dando a entender que ele queria mulheres mais jovens, mas não encontrou.

Nesses trechos, além das questões de gênero, o racismo não passa despercebido pela narradora, que desmascara João e seu interesse por mulheres que estejam ao seu alcance em suas aventuras sexuais: "Embora ela esteja no vasto leque que vai de morena claro ao escuro, com todas as etapas intermediárias que a cegueira, essa também cultural, de João não permite que ele reconheça, nomeie ou admita. Lola de aparência tão branquinha" (VIGNA, 2016, p. 133). Nesses comentários, observamos que o preconceito de João é identificado pelas opções da cor da pele, da beleza e da juventude da acompanhante que ele deseja contratar. 
Ao reconhecer que a maioria das garotas de programa que cruzou com João é morena e negra, a narradora reconhece que a prostituição é produto da desigualdade social e do machismo. Portanto, sua obra nos coloca frente a frente com uma sociedade que aceita a prostituição como um território econômico da masculinidade opressora. Por esse olhar, observamos que ao expor as intersecções identitárias dessas mulheres, a narradora questiona também o racismo estrutural que exclui a mulher pobre, parda/negra e prostituta. Tal interseccionalidade escancara "o racismo interceptado por outras estruturas" (AKOTIRENE, 2019, p. 29). Portanto, ao redesenhar de forma questionadora essa problemática, o texto de Vigna evidencia a condição econômica precária dessas mulheres.

Ao negar a condição desfavorável das prostitutas, João só está preocupado com sua performance sexual, como nos alerta a narradora: "garotas de programa não podem ser muito reais para João porque senão não funcionam como garotas de programa" (VIGNA, 2016, p. 59). A invisibilidade dessas mulheres para o protagonista é assustadora. Ele não consegue ir além da busca do prazer. Assim, a limitação do sexo com garotas de programa é também um limite existencial para ele, isto é, "uma espécie de tela, perfeita, sem nada que interfira no filme a ser passado. Ninguém nota uma tela, não antes de o filme começar, ou depois que acaba" (VIGNA, 2016, p. 59).

A necessidade que João tem de tratar as prostitutas como não sujeitos denota o quanto a existência e os corpos das mulheres subalternas, por sua condição de vulnerabilidade, refletem "uma escala social hierárquica, onde o subalterno ocupa o ínfimo espaço" (XAVIER, 2007, p. 47). Portanto, Vigna, ao tratar da decolonização da misógina que está por trás da prostituição, possibilita-nos refletir acerca de condutas masculinas de silenciamento dessas profissionais.

Para além da decolonização da misoginia, a escritora promove um processo de desconstrução do estereótipo das prostitutas. A esse respeito Ferrão, compara-o a uma allium cepa por "[...] ele ser composto por várias camadas, dispostas assim como as camadas de uma cebola, cujo produto final é uma figura imaginada, que não corresponde a um sujeito" (FERRÃO, 2018, p. 19). A despersonificação da prostituta é uma estratégia masculina de silenciamento. No texto de Vigna, essa regulação misógina não é tão diferente do silenciamento da esposa. Daí, destacamos a importância do título performático dessa narrativa que aproximar diferentes sujeitos femininos que passam pelo mesmo processo de aniquilamento. Essa soronidade é amarada pela perspicácia da narradora que dá voz a todas.

Portanto, no que tange ao processo de deslocamento das representações femininas, Vigna promove o afastamento das prostitutas da marginalização ao situá-las em eixos centrais do texto, reconhecendo diferentes subjetividades por trás das profissionais do sexo. Como no caso de Mariana, por quem a narradora passa a desconstruir o estereótipo desse tipo de mulher, pois é mãe de Gael e amiga com quem divide as despesas do apartamento. Mariana é vista como um sujeito com angústias e projetos de vida, que se transforma após o exercício da prostituição. Ela precisa se transformar de "[...] não pessoa em pessoa, o processo é doloroso, intimo. Põe Gael para brincar com alguma coisa. E começa. E é dificil. É dificil para ela limpar a maquiagem em frente ao espelho. O banho também é demorado e dificil" (VIGNA, 2016, p. 45).

Com diferentes estratégias de explorar o lugar de fala da prostituta, Elvira Vigna opta por um olhar irônico e pós-moderno para desnudar um padrão masculino egoísta, João, que não concede a outra o direito à fala. Ao dar voz às garotas de programa, por meio das histórias de João, essa obra nos coloca diante do silêncio de mulheres subalternas. Nesse tipo de narrativa, "as estratégias paródicas pós-modernas são frequentemente empregadas por artistas feministas para chamar a atenção para a história e poder histórico dessas representações culturais" (HUTCHEON, 1993, p. 9). Tal proposta estética prima por um jogo narrativo que questiona "o estatuto da própria literatura" para abrir espaço a vozes silenciadas pela colonialidade de gênero (GOMES, 2010, p. 52). 
Sendo assim, o uso do jogo estético que passa pelas tiradas irônicas e paródias como a narradora trata as aventuras de João. Com essas estratégias, Vigna visa contestar o ponto de vista machista de João que, ao narrar apenas seus feitos sexuais, silencia e objetifica as mulheres. A presença de uma narradora perspicaz e audaciosa revela, gradativamente, as dúvidas e inseguranças carregadas por esse homem predador, que foi educado para disputar território com seus colegas. Essa competição entre eles indica os limites de seus valores morais.

No que tange à constante necessidade de afirmação da masculinidade motivada, ora pelo próprio João, ora por aqueles que o cercam, concretiza-se por meio da posse do corpo da prostituta. Vigna trata essa questão como uma forma de identificação entre ele. Esse grupo de homens entende que para ser legitimamente reconhecido como um homem viril precisa demarcar uma posição de poder e respeito ante seus pares, com o intuito de mostrar que possui o vigor físico e moral que o torna merecedor de ocupar um lugar de prestígio no mundo masculino.

Nesse plano ficcional, as masculinidades retratadas estão relacionadas a valores morais que cultuam a liberdade sexual do homem em oposição a desqualificação da mulher. Tais normas regulam tanto o comportamento da esposa como das mulheres de fora, pois "[...] se pautam na possibilidade [homem] de ter livre acesso a várias mulheres e no modo como controla social e sexualmente a mulher escolhida para companheira" (MACHADO, 1998, p. 253-254). Na ficção de Vigna, esses códigos são colocados à prova pela narradora que, ironicamente, quebra ao adentrar pelo jogo de poder e de privilégio econômico dos homens que exploram o corpo das prostitutas:

O tema do poder.

O tema do poder entre prostituta e cliente é o que menos emplaca, nas nossas conversas no escritório.

Minha culpa. Quando o tema ensaiou se estender, cortei: "Para mim, vender a buceta ou o biceps é exatamente a mesma coisa".

[...] Para mim comparar buceta com biceps tem a vantagem de obliterar minha fragilidade. Porque uma coisa é ele discorrer, a partir de sua posição de macho, sobre um eventual poder feminino. Ele, bem firme, discorrendo paternalistamente sobre a possibilidade do poder de uma prostituta.

[...] Outra coisa bem diferente é ele se ver igual à prostituta. Ele à venda. Ou seu bíceps-buceta (VIGNA, 2016, p. 91-92).

Ao aproximar a posição do cliente da prostituta, essa obra decoloniza valores morais masculinos e ao questionar a posição de vítima que João projeta ao relativizar suas buscas incessantes de prostitutas. Como isso, a narradora promove um questionamento explícito à visão de meros objetos sexuados que João e seus amigos empregam a elas. Quanto à decolonização da masculinidade na obra, essa se realiza pelo fato de João não conseguir concretizar a "fantasia que tem de si de homem 'transgressor'" (SILVEIRA, 2017, p. 179). Além disso, não consegue adquirir a essência de uma masculinidade desejada e atravessada por uma superioridade detentora de força, invulnerabilidade e controle da própria sexualidade e da do outro. João torna-se, portanto, vítima da própria misoginia que impõe às mulheres.

Sendo assim, ao desvelar a economia simbólico-patriarcal que orienta as relações de poder entre os gêneros na sociedade, a obra de Vigna nos permitiu constatar o quanto a intersecção de violências impostas às mulheres em maior estado de vulnerabilidade é utilizada como estratégia pela ordem androcêntrica para mantê-las em um lugar de subalternidade.

Portanto, em seu romance, Elvira Vigna põe em xeque o "privilégio" masculino de apropriar-se do corpo feminino ao mesmo tempo em que decoloniza os valores misóginos de uma sociedade que relativiza o machismo que se projeta por meio da compra do silenciamento da prostituta e do culto da virilidade.

\section{Considerações finais}

Na leitura proposta neste artigo, ensaiamos uma reflexão que desloca o lugar da prostituta para dar visibilidade ao silenciamento estrategicamente imposto pelo discurso machista. Nesse trajeto, evidenciamos que a literatura de Elvira Vigna, por meio da representação de masculinidades opres- 
soras, desvela os processos de naturalização das violências praticadas contra as mulheres subalternas. Constatamos também que a postura irônica da narradora expõe as feridas da colonialidade de gênero reguladas para proteger o homem.

No trajeto interpretativo, podemos afirmar que Como se estivéssemos em palimpsesto de putas faz parte das produções literárias de autoria feminina marcadas por uma performance engajada contra a violência, pois põe em xeque os privilégios masculinos, que são denunciados por uma perspectiva interseccional de diferentes posições femininas, visto que "não se resiste sozinha à colonialidade do gênero. Resiste-se a ela desde dentro" (LUGONES, 2019, p. 372). Ao jogar com a intersecção entre a voz da narradora e das prostitutas, Vigna denuncia a perversa colonialidade que relativiza a posição do homem, mas aniquila essa profissional.

Em sua pesquisa sobre masculinidades, Lia Zanota Machado salienta que "estão surgindo novas formas e possibilidades de reeditar a ideia de 'virilidade' inscrita no imaginário datado, mas de longa duração do código de honra" (2001, p. 27). Por esse caminho, o feminismo, como um movimento que busca a igualdade entre os gêneros, além de continuar reivindicando melhores condições às mulheres, também está buscando um padrão de masculinidade que respeite os direitos da mulher.

Concluímos destacando que as performances identificadas em Como se estivéssemos em palimpsesto de putas são representações estéticas que nos remetem a reflexões sociais. O jogo de vozes entre a narradora e as prostitutas não deixa de fora o desmascaramento de códigos machistas incorporados às práticas sexuais. Esse recurso de dar voz às mulheres subalternas pulsa como uma estratégia de resistência. Ao desnudar a colonialidade sexual, Vigna expõe o silenciamento imposto ao sujeito feminino, tanto na violência simbólica, praticada nas relações familiares, como na violência sexual, normatizadas pelo poder masculino de comprar o corpo feminino.

Portanto, o intrincado jogo de vozes da obra de Elvira Vigna aponta o quanto a mulher ainda é subjulgada pelos códigos machistas. 0 palimpsesto de vozes que a narradora explora no seu malabarismo reforça sua performance feminista, entre as vozes que pulsam temos uma tênue fronteira entre as identidades da esposa, da amiga, da prostituta e de João. Deste modo, trata-se de um romance que revisa as posições de gênero, ao brincar com paradigmas culturais que aprisionam as mulheres à colonialidade sexual, e nos permite desvelar as sutilezas simbólicas usadas pela violência estrutural hegemônica para fundamentar as desigualdades de gênero e o silêncio proposital das mulheres.

\section{Referências}

AKOTIRENE, Carla. Interseccionalidade. São Paulo: Sueli Carneiro; Pólen, 2019

FERRÃO, Ana Carolina Schmidt. Desdobramentos da personagem prostituta: a guará subjetiva e o palimpsesto de estereótipos. 2018. 89 f. Dissertação (Mestrado em Teoria Literária) - Programa de Pós-Graduação em Letras, Pontificia Universidade Católica do Rio Grande do Sul, Porto Alegre, 2018. Disponivel em: http://repositorio.pucrs. $\mathrm{br} / \mathrm{dspace} / \mathrm{bitstream/10923/11376/1/000488555-Tex-}$ to\%2bCompleto-0.pdf. Acesso em: 21 mar. 2019.

GOMES, Carlos Magno. O romance pós-moderno feminino. Interdisciplinar, São Cristóvão, v. 10, n. 1, p. 45-53, 2010. Disponivel em https://seer.ufs.br/index. php/interdisciplinar/article/view/1253/1089. Acesso em: 15 mar. 2021.

HOLLANDA, Heloisa Buarque de. Explosão Feminista: arte, cultura, política e universidade. São Paulo: Companhia das Letras, 2018

HUTCHEON, Linda. Poética do pós-modernismo. Tradução de Ricardo Cruz. Rio de Janeiro: Jorge Zahar, 1991.

HUTCHEON, Linda. La politica de la parodia postmoderna. Traducción del inglés por Desiderio Navarro. Revista Criterios, [S. I.], edición especial, p. 1-18, 1993.

LIMA, Francisca Sueli da Silva; MERCHÁN-HAMANN, Edgar; URDANETA, Margarita; DAMACENA, Giseli Nogueira; SZWARCWALD, Célia Landmann. Fatores associados à violência contra mulheres profissionais do sexo de dez cidades brasileiras. Cadernos de Saúde Pública. Brasília, v. 33, n. 2, p. 1-16, 2017. Disponível em: https://repositorio.unb.br/bitstream/10482/30637/1/ ARTIGO_FatoresAssociadosViol\%c3\%aaencia.pdf. Acesso em: 10 jun. 2020.

LORDE, Audre. Não existe hierarquia de opressão. In: HOLLANDA, Heloisa Buarque de (org.). Pensamento feminista: conceitos fundamentais. Rio de Janeiro: Bazar do tempo, 2019. p. 235-236.

LUGONES, Maria. Rumo a um feminismo descolonial. In: HOLLANDA, Heloisa Buarque de (org.). Pensamento feminista: conceitos fundamentais. Rio de Janeiro: Bazar do tempo, 2019. p. 357-377. 
MACHADO, Lia Zanotta. Masculinidade, sexualidade e estupro. Cadernos Pagu, [S. I.], v.11, p.231-273, 1998.

MACHADO, Lia Zanotta. Masculinidades e violências. Gênero e mal-estar na sociedade contemporânea.. Brasilia: Universidade de Brasília, Departamento de Antropologia, 2001. (Série Antropologia, n. 290).

SEGATO, Rita Laura. Las estructuras elementales de la violencia: contrato y status em la etiologia de la violencia. Brasília: Departamento de Antropologia UnB, 2003. (Série Antropologia).

SILVEIRA, Suzane Morais da Veiga. A ressubjetivação da mulher e a desconstrução do mito do homem moderno em Como se estivéssemos em palimpsesto de putas, de Elvira Vigna. Fórum de Literatura Brasileira Contemporânea, Rio de Janeiro, v. 9, n. 18, p. 175-203, 2017.

SPIVAK, Gayatri. Pode o subalterno falar? Tradução de Sandra Regina Goulart Almeida, Marcos Pereira Feitosa e André Pereira. Belo Horizonte: Editora UFMG, 2010.

VIGNA, Elvira. Como se estivéssemos em palimpsesto de putas. 1. ed. São Paulo: Companhia das Letras, 2016.

XAVIER, Elódia. Que corpo é esse? O corpo no imaginário feminino. Florianópolis: Ed. Mulheres, 2007.

ZOLIN, Lúcia Osana. Crítica Feminista. In: BONNICI, Thomas; ZOLIN, Lúcia Osana (org.). Teoria literária: abordagens teóricas e tendências contemporâneas. Maringá: Eduem, 2009. p. 181-203.

\section{Gardênia Dias Santos}

Mestre em Letras pelo Programa de Pós-Graduação em Letras da Universidade Federal de Sergipe (PPGL/ UFS), em São Cristóvão, SE, Brasil. Professora da educação básica em Sergipe.

\section{Carlos Magno Gomes}

Pós-Doutor em Estudos Literários pela Universidade Federal de Minas Gerais (UFMG), em Belo Horizonte, MG, Brasil. Doutor em Literatura pela Universidade de Brasilia (UnB), em Brasília, DF, Brasil. Professor da Universidade Federal de Sergipe (UFS), em Itabaiana, SE, Brasil.

\section{Endereço para correspondência}

Gardênia Dias Santos

Universidade Federal de Sergipe

Cidade Universitária Prof. José Aloísio de Campos

Av. Marechal Rondon, $\mathrm{s} / \mathrm{n}$

Jardim Rosa Elze, Prédio Departamental II, sala 17

49100-000

São Cristóvão, SE, Brasil
Carlos Magno Gomes

Universidade Federal de Sergipe

Campus Universitário Prof. Alberto Carvalho

Av. Vereador Olimpio Grande, s/n

Secretaria do Profletras

49.500-000

Itabaiana, SE, Brasil

Os textos deste artigo foram revisados pela Poá Comunicação e submetidos para validação do(s) autor(es) antes da publicação. 